\title{
Asymptomatic costal exostosis with thickening in the pericardium: a case report
}

\author{
Toru Kameda', Takashi Makino', Takamitsu Sakai', Satoshi Koezuka', Hajime Otsuka', Yoshinobu Hata', \\ Naobumi Tochigi ${ }^{2}$, Kazutoshi Shibuya ${ }^{2}$ and Akira lyoda ${ }^{1^{*}}$
}

\begin{abstract}
Background: Costal exostosis is a benign condition that sometimes requires emergent surgery because of associated hemothorax; in addition, there have been cases with malignant transformation to chondrosarcoma. Here, we describe an asymptomatic patient who underwent thoracoscopic resection for primary costal exostosis.

Case presentation: A 16-year-old male was found to have a bow-shaped shadow on a chest X-ray. Chest computed tomography revealed a rod-like mass with a soft tissue shadow adjacent to the left fifth rib. A thoracoscopic partial resection of the left fifth rib was performed. Intraoperative findings included thickening of the pericardium near the tip of the growth and erosion of the visceral pleura of the left lung. The resected specimen was diagnosed as a primary costal exostosis based on histopathological findings.
\end{abstract}

Conclusions: We review the published literature on costal exostosis and discuss the surgical indications of asymptomatic cases.

Keywords: Exostosis, Rib, Asymptomatic, Surgical indication

\section{Background}

A costal exostosis is a benign growth capped by cartilage, which protrudes from a rib. It may sometimes require emergent surgery because of an associated complication such as damage to an intrathoracic organ $[1,2]$, and there have been some cases that have transformed to chondrosarcoma [3]. We performed a resection of an asymptomatic primary costal exostosis that had been incidentally discovered on a chest X-ray and I found the exostosis was accompanied with wall thickening in the pericardium and visceral pleura of the left lung. We discuss the indications for surgery for patients with costal exostosis, focusing on asymptomatic cases.

\section{Case report}

A 16-year-old male was found to have a bow-shaped shadow to the left of the middle lung field on chest $\mathrm{X}$ ray. Chest computed tomography (CT) revealed a rodlike mass with a soft tissue shadow adjacent to the left fifth rib (Fig. 1). The diagnosis was primary costal

\footnotetext{
* Correspondence: aiyoda@med.toho-u.ac.jp

${ }^{1}$ Division of Chest Surgery, Toho University School of Medicine, Tokyo, Japan Full list of author information is available at the end of the article
}

exostosis of the left fifth rib, and the growth was resected because of the risk of damage to intrathoracic organs.

The patient underwent thoracoscopic partial resection of the left fifth rib. An approximately 50-mm long structure protruding from the fifth rib into the chest cavity was observed through the thoracoscope. Thickening in the pericardium near the tip of the structure and erosion of the visceral pleura of the left lung were also seen (Fig. 2). The cartilage cap could not be identified, and it was resected with the fifth rib.

Histopathological examination of the resected specimen found that the growth was composed of mature bone tissue; there were no atypical cells or bone marrow within the growth. No cartilage cap was found, but thickened fibrotic tissue was observed and thought to represent inflammatory changes caused by degeneration and omission or mechanical irritation of the cartilage cap. There were no signs of malignant changes, and the growth was diagnosed as a primary costal exostosis.

\section{Discussion}

Exostosis has accounted for $50 \%$ of primary benign bone tumors and has been observed to occur at the 


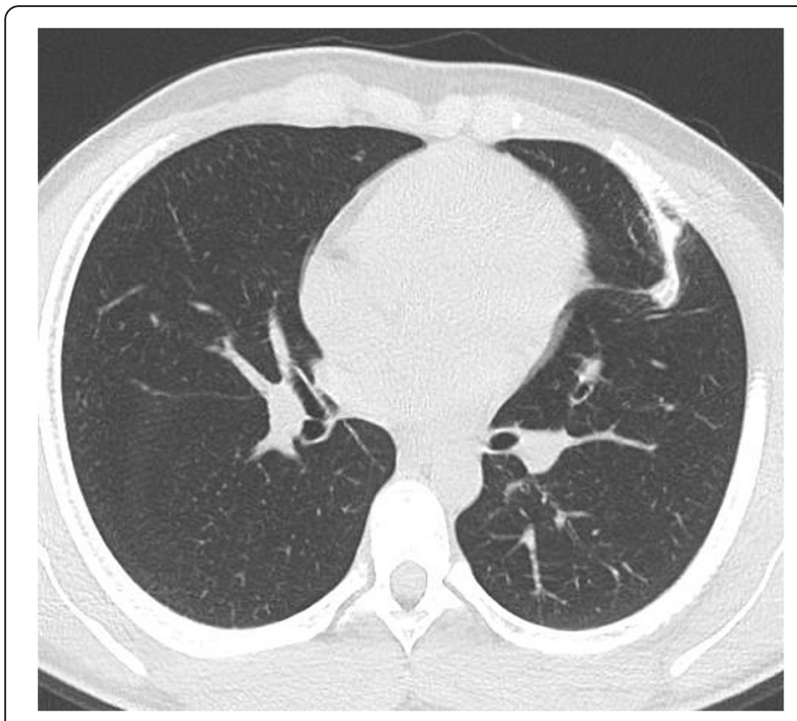

Fig. 1 Chest computed tomography scan shows a rod-like mass with a soft tissue shadow adjacent to the left fifth rib

metaphysis of long bones or originate from the surface of flat bones [4]. It generally occurs at the proximal femoral or distal tibial metaphysis [1]. Exostosis of the rib makes up a small proportion of the cases of exostosis [4].

Primary exostosis occurs as solitary or multifocal lesions, and multiple exostosis is a hereditary disease that occurs in infants $[5,6]$. Hereditary multiple exostosis is a rare disorder characterized by the formation of exostoses in many locations. It is associated with mutations in the EXT genes and is manifested by skeletal deformities caused by abnormal bone growth [5].

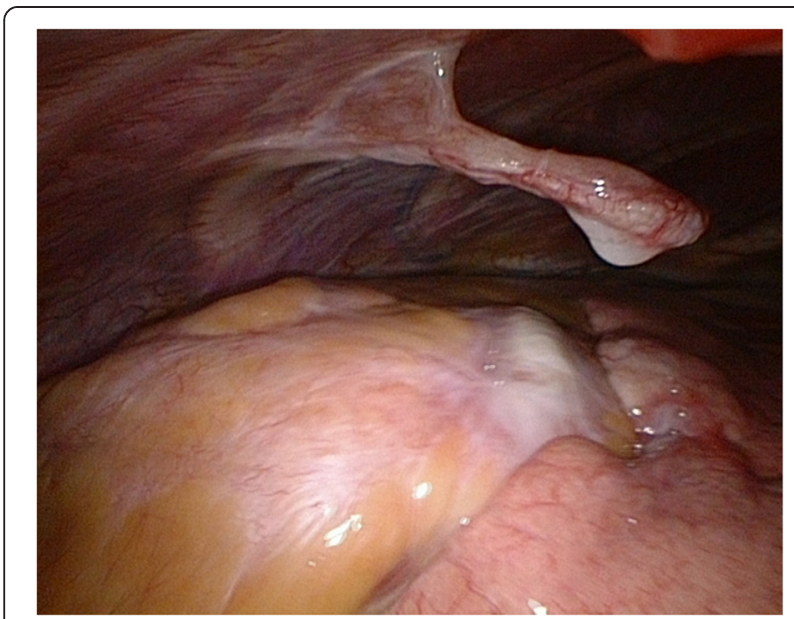

Fig. 2 View through the thoracosope shows an approximately $50-\mathrm{mm}$ long structure protruding from the fifth rib into the chest cavity. Thickening of the pericardium near the tip of the structure and erosion of the visceral pleura of the left lung are also visible
Solitary exostosis occurs in both infants and adults $[1,4]$, and is generally asymptomatic. When an X-ray diagnosis of an asymptomatic case is not definitive, a chest CT is useful. Symptomatic cases of costal exostosis have presented with swelling, hiccup [7], chest pain [7], pneumothorax [4, 8, 9], or hemothorax $[1,2]$. Hemothorax is thought to result from trauma caused by the costal exostosis to the pleura [6], diaphragm $[1,10]$, lung $[11,12]$, or heart [13]. Cases at risk of life-threatening damage to intrathoracic organs should be resected surgically.

Past reports of organ damage due to costal exostosis have described longitudinal lacerations of the diaphragm and pericardium adjacent to the tip of the exostosis that were caused by movements during respiration. Even in cases such as ours, with asymptomatic anterior left fifth costal exostosis, histopathological changes were seen in the pericardium and lung. In a patient with anterior left fourth rib exostosis, thickened pericardium and visceral pleura possibly caused by scratch have been reported [14]. Although in our patient the distance between an intrathoracic organ and the exostosis was long, lifethreatening damage to an intrathoracic organ due to respiratory movements was possible. Even if the tip of protrusion seems apart enough from the pericardium or diaphragm, anterior costal exostosis can come in touch with these intrathoracic organs during the movement of the chest wall, resulting in just a scratch or a fatal injury according to the strength of the external pressure. Therefore, preventive surgical treatment should be considered especially for the anterior left costal exostosis.

Malignant transformation of an exostosis to chondrosarcoma [15] is relatively rare; the risk of a solitary exostosis transforming to chondrosarcoma is $1-2 \%$, and for multiple osteocartilaginous exostoses is 5-25\% [3]. Chondrosarcoma should be suspected if a lesion continues to grow in the patient after puberty or localized pain develops [4].

Because of the risks of hemothorax, other lifethreatening complications, and malignant transformation, prophylactic surgical resection should be considered for patients with costal exostosis. Care should be taken to perform resections with adequate margins in order not to leave the residual cartilage cap, especially for cases where the extent of the cartilage cap cannot be determined, and for cases of exostosis occurring at sites other than the ribs. There have been reports of cases of exostosis involving other bones that have developed postoperative recurrence because the initial resection was inadequate.

\section{Informed consent}

Written informed consent was obtained from the patient for publication of this case report and any accompanying images. A copy of the written consent is 
available for review by the Editor-in-Chief of the Journal of Cardiothoracic Surgery.

\section{Conclusions}

We reviewed the published literature on costal exostosis and discussed the surgical indications of asymptomatic cases. Prophylactic surgical resection should be considered for patients with costal exostosis.

\section{Competing interests}

The authors declare that they have no competing interests.

\section{Authors' contributions}

All authors participated in the design of the case report and helped to draft the manuscript. All authors read and approved the final manuscript.

\section{Acknowledgements}

This study was supported in part by a Grant-in-Aid for Scientific Research (C) 15 K10272 from the Japanese Ministry of Education, Culture, Sports, Science and Technology, and a Research Promotion Grant to Akira lyoda from Toho University Graduate School of Medicine (No.15-02)

\section{Disclosures}

The authors have no funding, no financial relationships, and no conflicts of interests.

\section{Author details}

'Division of Chest Surgery, Toho University School of Medicine, Tokyo, Japan. 2Department of Surgical Pathology, Toho University School of Medicine,

Tokyo, Japan.

Received: 7 August 2015 Accepted: 29 February 2016

Published online: 05 March 2016

\section{References}

1. Reynolds JR, Morgan E. Haemothorax caused by a solitary costal exostosis. Thorax. 1990:45:68-9.

2. Nakano T, Endo S, Nokubi M, Tsubochi H. Hemothorax caused by a solitary costal exostosis. Ann Thorac Surg. 2009:88:306

3. Garrison RC, Unni KK, Mcleod RA, Pritchard DJ, Dahlin DC. Chondrosarcoma arising in osteochondroma. Cancer. 1982:49:1890-7.

4. Khosla A, Parry RL. Costal osteochondroma causing pneumothorax in an adolescent: a case report and review of the literature. J Pediatr Surg. 2010;45: 2250-3.

5. Cowles RA, Rowe DH, Arkovitz MS. Hereditary multiple exostoses of the ribs: an unusual cause of hemothorax and pericardial effusion. J Pediatr Surg. 2005:40:1197-200.

6. Uchida K, Kurihara Y, Sekiguchi S, Doi Y, Matsuda K, Miyanaga M, et al. Spontaneous haemothorax caused by costal exostosis. Eur Respir J. 1997:10:735-6.

7. Alifano M, Morcos M, Molina T, Regnard JF. An unusual cause of hiccup: costal exostosis. Treatment by video-assisted thoracic surgery. Eur J Cardiothorac Surg. 2003;23:1056-8.

8. Imai K, Suga $Y$, Nagatsuka $Y$, Usuda J, Ohira T, Kato $H$, et al. Pneumothorax caused by costal exostosis. Ann Thorac Cardiovasc Surg. 2014;20:161-4.

9. Pollitzer RC, Harrell GT, Postlethwait RW. Recurrent pneumothorax associated with hereditary deforming chondrodysplasia; report of a case apparently due to puncture of the lung by an exostosis of a rib. N C Med J. 1952;13:668-73.

10. Simansky DA, Paley M, Werczberger A, Bar Ziv Y, Yellin A. Exostosis of a rib causing laceration of the diaphragm: diagnosis and management. Ann Thorac Surg. 1997:63:856-7.

11. Bini A, Grazia M, Stella F, Petrella F. Acute massive haemopneumothorax due to solitary costal exostosis. Interact Cardiovasc Thorac Surg. 2003;2:614-5.

12. Takata K, Suzuki K, Kurosaki Y. Spontaneous hemothorax in hereditary multiple exostosis involving the ribs. Radiat Med. 2008;26:39-41.
13. Buchan KG, Zamvar V, Mandana KM, Nihal E, Kulatilake P. Juxtacardiac costal osteochondroma presenting as recurrent haemothorax. Eur J Cardiothorac Surg. 2001;20:208-10.

14. Nakano T, Endo S, Tsubochi H, Tetsuka K. Thoracoscopic findings of an asymptomatic solitary costal exostosis: is surgical intervention required? Interact Cardiovasc Thorac Surg. 2012;15:933-4.

15. Liu W, Kong D, Tang J, Yu F. Giant costal osteochondroma in a man with multiple exostoses. Ann Thorac Surg. 2013:96:675-7.
Submit your next manuscript to BioMed Central and we will help you at every step:

- We accept pre-submission inquiries

- Our selector tool helps you to find the most relevant journal

- We provide round the clock customer support

- Convenient online submission

- Thorough peer review

- Inclusion in PubMed and all major indexing services

- Maximum visibility for your research

Submit your manuscript at www.biomedcentral.com/submit 